International Journal of Linguistics, Literature and Translation

ISSN: 2617-0299 (Online); ISSN: 2708-0099 (Print)

DOI: $10.32996 /$ ijllt

Journal Homepage: www.al-kindipublisher.com/index.php/ijltt

IJLLT

\title{
Grammatical Transitivity and Indirect Speech Combination in Action: Voices from Characters in Helon Habila's Oil on Water (2011)
}

\author{
Innocent Sourou KOUTCHADÉ \\ Université d'Abomey-Calavi (UAC), Benin
}

$\square$ Corresponding Author: Innocent Sourou KOUTCHADÉ, E-mail: Koutchade2@yahoo.fr

\begin{tabular}{ll}
\hline ARTICLE INFORMATION & ABSTRACT \\
\hline $\begin{array}{l}\text { Received: } 16 \text { October } 2021 \\
\text { Accepted: } 14 \text { November } 2021\end{array}$ & $\begin{array}{l}\text { In mass communication, the material process use makes it easy to lay emphasis on the } \\
\text { participants' actions, events, and circumstances of their occurrence, while mental } \\
\text { published: } 30 \text { November } 2021\end{array}$ \\
pol: 10.32996/ijlt.2021.4.11.10 & $\begin{array}{l}\text { indirect speech, it characterizes the version always used by messengers, public } \\
\text { announcers, journalists, and reporters. This study aims to analyze Transitivity and }\end{array}$ \\
\hline KEYWORDS & $\begin{array}{l}\text { Indirect Speech in clauses ingrained and identified in some passages taken from Helon } \\
\text { Habila's Oil On Water (2011). One of the major principles of Systemic Functional }\end{array}$ \\
$\begin{array}{l}\text { Systemic Functional Linguistics } \\
\text { (SFL), Ideational Metafunction, }\end{array}$ & $\begin{array}{l}\text { Linguistics is that the exploration of the Transitivity properties (processes, participants, } \\
\text { and circumstances) in a text leads to draw conclusions about the question -"who does } \\
\text { Speech, Journalistic Experience }\end{array}$ \\
$\begin{array}{l}\text { what to whom, under what circumstances?"? In order to deliver the set objectives, the } \\
\text { ongoing study specifically draws on the principles of experiential meaning to get data } \\
\text { from the selected extracts and, focuses on describing the clauses containing reported } \\
\text { speeches. By following the mixed research methods guiding principles, this research } \\
\text { work has generated some data which enable to come up with a conclusion on the } \\
\text { psychological and psychosomatic states of the participants as well as on the assigned } \\
\text { status adopted by some characters. That correlates them to reporters and journalists. } \\
\text { This research work has enabled me to develop another. This paper has made it easy to } \\
\text { have another view about Helon Habila's messages and the way they are conveyed } \\
\text { throughout his novel. }\end{array}$
\end{tabular}

\section{Introduction}

Human beings, in their daily interactions with their peers, are called upon to use language. Hence, language is an important ability for them. Due to its importance, many scholars through several generations devoted their time to language study. The different studies gave birth to a science: Linguistics. Halliday and Webster (2006) defined this science as "the scientific study of language". Through the years, this science has been subdivided into sub-disciplines that study, each one, a particular aspect of language in a particular context. Along with these subdivisions, several schools have emerged. Among those schools, there is Structural Linguistics (or Structuralism) which is derived from Ferdinand de Saussure's works. According to structuralists, language is a self-contained, self-regulating semiotic system whose elements are defined through their relationship to other elements within the system (Matthews, P. H.). Many approaches can be found in this school such as Functional Linguistics. Halliday (2004) contends that Functional Linguistics is characterized by taking systematically into account the speaker's and hearer's side, and the communicative needs of the speaker and of the given language community. This approach led to systemic functional Linguistics (devised by Michael Halliday) which is an approach to linguistics, among functional linguistics that considers language as a social semiotic system (Caffarel, Martin \& Matthiessen, 2004).

Halliday (1985) has identified in his approach three metafunctions that are: ideational (how we represent reality in language), interpersonal (the grammatical choices that enable speakers to enact their complex and diverse interpersonal relations) and textual (who is about the organization of the conveyed message). The ideational metafunction is declined into two components: experiential meaning and logical meaning. Experiential meaning involves a Transitivity pattern, which is our concern in this thesis. Indeed, this paper focuses on Transitivity and Indirect speech analyses in Helon Habila's Oil on Water. In fact, Indirect speech

Copyright: (c) 2021 the Author(s). This article is an open access article distributed under the terms and conditions of the Creative Commons Attribution (CC-BY) 4.0 license (https://creativecommons.org/licenses/by/4.0/). Published by Al-Kindi Centre for Research and Development, London, United Kingdom. 
enables to report someone or one's own discourse, may it be an affirmation, interrogation, request, or order. Most of the time, the application of this grammatical principle in discourse implies the omission of conjunction that follows those natural introducing verbs such as say, tell, think, etc... Beyond the direct modifications of punctuation, the logical reformulations emerging as a result of indirect discourse also entails time and location circumstantial, pronouns, modals as well as determinants changes.

The cardinal principles developed in indirect discourse assume the existence of an interpersonal communication ignited by somebody and conveyed by a reporter. Interpersonal communication works on some prerequisites such as interpersonal relationships, interconnection, and interdependence between two or more participants. In order to fully understand this relationship, it is paramount to be aware of the role communication plays in the exchange of both verbal and nonverbal messages between at least two people. At this stage, three research questions come to mind:

i) How is the experiential function realized in Habila's Oil on Water?

ii) How does indirect discourse contribute to the understanding of the participant's role in the novel?

iii) To what extent are the transitivity and indirect speech combinations correlated with journalistic and reporting experience in fiction?

In order to reach its goal, this research has adopted the mixed research methodology as a guiding principle. It proceeds by describing and discussing the selected passages from the qualitative method angle. The so generated data are screened, processed, analyzed, computed from the qualitative method angle. The overall objective of this research venture is to correlate the use of direct and indirect transitive processes and indirect speech to journalistic and reporter's experience in Helon Habila's fiction. More specifically, this research work has to:

1- Describe the experiential parameters ingrained in the passages under study;

2- Identify and analyze the indirect speech clauses the passages under study;

3- Combine and correlate the experiential properties and indirect speeches to the journalistic experience of the writer.

Carrying out the three above-mentioned activities should certainly bring about some findings, thereby the deliverables of this study. The consideration and discussion of those findings enable to establish a clear correlation between the use of some ideational devices, in particular those pertaining to transitivity, and indirect speech with the reporter and journalist of investigation's writing style.

\subsection{Theoretical Framework Serving as Backbone to the Study}

In order to perform a Discourse Analysis or deepen comprehension of a text, there are a variety of theories that can be applied to Literature. Each one of those theories has a structure and its own methodology. For an understanding of the theory adopted in this study, it would be worthy of exploring the theoretical framework of that theory. This study is based on the Systemic Function Linguistics, a theory designed by Michael Halliday (Halliday, 1961). It has been "described as a functional-semantic approach to language which explores both how people use language in different contexts and how language is structured for use as a semiotic system" (Eggins, 2004).

That theory contends that language operates along three metafunctions: ideational, interpersonal, and textual. As far as ideational metafunction which is the cornerstone in this study is concerned, it is about "how one represents experience in language" (Eggins, 2004). In the same vein, Eggins explains that the ideational metafunction of language involves two components: the experiential meaning of the clause and its logical meaning as established between clauses in the text. Experiential meaning is expressed through the system of process types, with the implication of associated participants' roles and configurations (Alaei \& Ahangari, 2016). Six (06) different categories of the process are identified: material, mental, verbal, behavioral, existential, and relational.

1.1.1 Material Process: Those processes describe processes of doing, usually concrete and tangible actions. The semantic definition of material processes is that "some entity does something, undertakes some action". Actions involve actors or participants who are realized by nominal groups. Two different types of material processes can be identified: middle or intransitive material processes and effective or transitive material processes. Middle or intransitive material processes are "processes in which there is only one participant", clauses in which "someone does something" (Eggins, 2004). We can identify them by asking "what did x do?"

As for effective or transitive material processes, they are processes in which there are two (or more) participants, clauses in which "someone does something, and the doing involves another entity." (Eggins, 2004). If they involve two participants, we can probe them by asking "what did $x$ do to $\mathrm{y}^{\prime \prime}$; if they involve three participants, we ask "what did $\mathrm{x}$ do to $\mathrm{y}$ to $z$ ". Effective clauses can be either active or passive. 
1.1.2 Mental Process: Mental processes are processes about psychological reactions: thoughts, feelings, perceptions. They encode the meaning of feeling or thinking. Halliday divides mental process verbs into three classes: cognition (verbs of thinking, knowing, and understanding), affection (verbs of liking, fearing), and perception (verbs of seeing, hearing).

1.1.3 Behavioural Process: These are physiological and psychological behavior. Halliday describes these processes semantically as a 'halfway house' between mental and material processes. That is, the meanings they realize are mid-way between materials on the one hand and mental on the other. They are in part about action, but it is an action that has to be experienced by a conscious being.

1.1.4 Verbal Process: These are processes of verbal action: saying and all its many synonyms, including symbolic exchanges of meaning. A verbal process contains three participants: Sayer, Receiver, and Verbiage. The Sayer, the participant responsible for the verbal process, does not have to be a conscious participant (although it typically is), but anything capable of putting out a signal. The Receiver is the one to whom the verbal process is directed: the Beneficiary of a verbal message, occurring with or without a preposition depending on the position in the clause. The Verbiage is a nominalized statement of the verbal process: a noun expressing some kind of verbal behavior (Eggins, 2004).

1.1.5 Relational Process They cover many different ways in which being can be expressed. There are two main types of relational processes: Attributive and Identifying processes. Each one of these two types is declined into intensive, circumstantial, possessive, and causative relational processes.

1.1.6 Existential Process: these involve the use of the word 'there'. Eggins (2004) explains that "there when used in existential processes, has no representational meaning: it does not refer to a location" (p.214). Existential processes typically employ the verb 'be' or synonyms such as 'exist, arise, or occur'. The only obligatory participant in an existential process that receives a functional label is called the Existent. This participant, which usually follows the 'there is/are' sequence, maybe a phenomenon of any kind, and is often in fact an event (Alaei \& Ahangari, 2016). By and large, Systemic Functional Linguistics theory encompasses three cardinal metafunctions, namely: ideational, interpersonal, and textual. The ideational metafunction is about "how we represent experience in language". It involves two components: the experiential meaning in the clause and the logical meaning between clauses. The experiential meaning is expressed through the system of processes guiding the transitivity. Six (06) different types of processes are identified: material processes, mental processes, verbal processes, behavioral processes, existential processes, and relational processes. Each one of those process types goes along with the specificities that distinguish it from the others. The identification of those processes through different extracts allows for analyzing them. Each of the above-mentioned process types goes along with its specific participants as highlighted in Table 1.1 below.

Table 1. 1: Processes with their Related Participants (adapted from Bloor and Bloor, 2004: 132)

\begin{tabular}{|l|l|}
\hline Processes & Participants \\
\hline Material & Actor, Goal, Beneficiary, Range \\
\hline Mental & Senser, Phenomenon \\
\hline Relational & Carrier/attribute, Token/Value, Possessor/Possessed \\
\hline Verbal & Sayer, Receiver, Verbiage \\
\hline Behavioral & Behaver, Behaviour \\
\hline Existential & Existent \\
\hline
\end{tabular}

\section{Literature Review \& Methodology}

Pursuant to Halliday's research works, many scholars and researchers have carried out several conducted many investigations regarding transitivity patterns in fictional works in order to have a deeper understanding of their contents. In order to avoid plagiarism, copy and paste, repetitions as well as redundancy; it has been absolutely necessary to dig into the findings of the previous research works so far carried out by the pioneers and senior scholars. Scrutinizing previous research works in this field enables us to validate the authenticity of the ongoing research. The second paragraph under this section provides a thorough explanation about the methodological guidance followed so as not to go about an inquiry without benchmark and compass.

\subsection{Review of some Previous Scholarships}

In a comparative study conducted on transitivity analysis applied to Chinua Achebe's Arrow of God and Ngugi Wa Thiong'o's Petals of Blood, which have served as corpuses, Daniel T. Yokossi and Leonard A. Koussouhon (2017) have tapped into the Transitivity theory with a view to digging into Chinua Achebe's and Ngugi Wa Thiong'o's fiction so as to unravel the plots and thereby contribute to bettering their understanding. The final goal of the article is to end up comparing both authors' pieces of writing 
based on the findings. Three hypotheses had been put forth. The authors have in various ways, used the resources of the English language to express their experience in the selected texts. Second, in their creative process of writing, both authors have either consciously or subconsciously chosen certain linguistic items over others to represent their personal experience or event as well as that of their communities for stylistic effects. In a more specific view, Achebe and Ngugi associate or foreground some specific transitivity devices with particular characters for ideological, thematic, and/or aesthetic purposes. The third and final hypothesis is that both writers' pieces of literary work share, to some extent, similarities though the scholars contend that they largely differ based on their epoch of production and publication; and also because Ngugi posits that "literature written by Africans in a colonial language is not African literature, but "Afro-European literature." The methodology used to carry out this research work has considered the qualitative paradigm which develops through random sampling of the passages to be analyzed. As such, two extracts have been taken from each of the two selected novels.

The analysis carried out has consisted in generating and collecting data from Chinua Achebe's and Ngugi Wa Thiong'o's fiction. These data have then linguistically been examined to bring out the novels' experiential meaning. Besides, some statistic tables have been drawn up for better visibility of the linguistic features displayed by the analyzed extracts, and for a better interpretation of the findings. It emerges from the different analyses that the most frequently occurring processes are not only the material, but also the mental, the verbal, and the intensive attributive. The least frequently occurring process types are the existential, the circumstantial, and the Causative circumstantial. As a matter of fact, the material process type is noticeably predominant over the other types in the overall extracts. This is understandable in so far as most clauses in the texts are about happenings and doings. Furthermore, there is a large diversity of participants involved in the described process. Most of them are encoded in nominal groups which are on the whole either animate human beings or inanimate things.

Nevertheless, some participants are encoded in pronouns which, again, are referents for either human beings most frequently, or inanimate beings. Concerning the circumstances, except for the Cause circumstances, all the other types of circumstances are registered throughout the four extracts through both location and manner circumstances prevail over the others. Discussing the findings of the research, Yokossi and Koussouhon have underscored the fact that not all material process encodes concrete or tangible actions. As a matter of fact, some are "dematerialized.", that is, some process appears to be material but actually mean other process types. Some other Material processes do not encode concrete actions though denoting concrete actions at first sight. Furthermore, they noticed that the fewer number of the intransitive material processes in some extracts reveals firstly, the limitations of the people's own actions; secondly, a people's world view which in general cannot transcend these limitations but within which they may arise, and thirdly, a dip apprehension of the superior powers of the others represented by the rare intrusion of an intransitive clause.

Koussouhon and Dossoumou (2015) by their side, in the article "Exploring Ideational Metafunction in Helon Habila's Oil on Water: A re-evaluation and redefinition of African Women's Personality and Identity through Literature", published in 2015, aimed to apply some of the principles guiding Systemic Functional Grammar (SFG) to the novel. More specifically, the inquiry will dig into the grammar of experiential meaning through its material, mental, relational, behavioral, verbal, and existential processes. Another aim of the article is to shed the systemic functional grammar projector's light on how Helon Habila encodes journalistic experience through meanings to create, adapt and manage personal and interpersonal relations in the novel Oil on Water. Eventually, the discussion of the linguistic findings resulting from the analyses culminates in asserting that the redefinition of African women's personality and identity in African fiction is a timely endeavor that both African male and female writers of the new millennium should and must struggle to champion so as to revert the former unfavorable image and picture that some African and nonAfrican fiction is used to portraying. The Transitivity analyses in the article had been carried out on two extracts drawn from Oil on Water (2011). The two extracts have been split and structured into clauses. Then process types have been identified in the extracts, counted, and tabularized. The results from the analyses pointed out that three out of the six processes, viz. Material processes (45.50\%), Mental (18.25\%), and Relational (17.71\%) processes sharing unequal proportions are predominant. Apart from the existential processes that appear in very low (almost negligible) proportion $(01.08 \%)$, the other process types, viz, behavioral and verbal though appearing with less significant dominance with their varied proportions, respectively, $09.80 \%, 07.63 \%$ enhance this. The discussion made us know that the use of various and varied semantic representations- names, ad hoc description, and recoverable reference means that all the characters performing in the extracts as Sensers are animate beings- male and female. This suggests that there are in the extracts some participants (senser, phenomenon) who are consciously, intellectually, affectively involved in the situation under description. Moreover, an inclusive characterization adopted by the writer by focalizing the striking actions of the extracts understudy denotes a gender-balanced and inclusive society where varying roles are ascribed and assigned to women who feel and express the same intellectual, physiological, social, and affective needs as their male counterparts. The application of the Transitivity model to the analysis of the text has demonstrated that ideational meaning is a useful tool for unraveling how a given text constructs its world, characters, and actions in terms of who is doing what to whom, where, when, why and with what. 
Boukari and Koussouhon (2018) have pointed out the overall message conveyed in Gabriel Okara's The Voice (2018). The article focuses on the investigation of the ideational metafunction through a transitivity analysis. The researchers have posited two hypotheses for the work: the first one is that the study contributes with enough scientific evidence to reveal that the main character Okolo's "search for it" is the main topic that runs along with most pages of the novel. The second one is that throughout the different process types that occur in the selected text, one can realize that it is all about man's perpetual need to always take action, to understand the meaning of life, to set a fair society, and to reach salvation. To apply the Transitivity Model to the novel, two extracts have been chosen. After splitting each sentence into its (numbered) clauses, each clause had been split into constituents. The Transitivity patterns are identified, counted, and encoded in tables of statistics for the sake of quantitative analysis. The identified patterns are accounted for and the implications of meaning are spelled out in the section of the discussion. The analyses pointed out that processes are diversely distributed in the two extracts. There are many more material processes in extract 1 than in extract 2 . In extract 1 material processes rank first, mental processes rank second, followed by behavioral processes, then relational processes rank fourth with a majority of attributive processes. So, the text is also concerned with describing participants. The only relational process which is not attributive is rather a possessive one. Verbal processes rank fifth and there is no existential process. In extract 2 relational processes rank first with a large rate of relational processes; material processes rank second here, followed by mental processes ranking third, then verbal processes. Existential processes rank fifth and finally behavioral processes. It emerges from the discussion that all the processes that discussed do look or sound material but they do not happen in the physical world. They take place in the mind of an interactant. So, they are particular mental processes, especially cognitive ones, which suggest that the text is an intellectual concern.

Alaei and Ahangari (2016), intending to determine how ideology or opinion is expressed in Joseph Conrad's Heart of Darkness and what kind of lexico-grammatical strategies are used in the first part of the novella to convey the author's ideological meaning, used qualitative research methodology, taking into consideration Ideational metafunction. They hypothesize that by focusing on the lexico-grammatical choices in the transitivity system of the structure of the clauses, they can shed light on the ideational meaning in the first section of the story. Moreover, by examining the transitivity patterns in text, they can explain how the field of situation is being constructed. The findings show that material, relational and mental processes are the most used. Furthermore, most actors are animate. Talking about circumstances, manner, and location (space) are most used. From the discussions, the authors point out that the high amount of positive actor description used for Marlow as the protagonist of the story was ideological in favor of an anti-imperialistic character. Textual meaning analyzed on the main paragraph with the feasible maneuver features demonstrated that linguistically the author's ideology has been successfully expressed as literarily; syntax and semantics work their own ways in the same direction to imply the facts which are done in the past and brought about the European imperialism, having its whole effect on the lives of Africans.

Akogbeto and Koukpossi (2015) in a move to explore gender issues in Wole Soyinka's The Lion and the Jewel through systemic functional linguistics and critical discourse analysis perspective. The aim of the study is to have a critical look at the character's idiolect viz the way language is used by male and female characters through a lexico-grammatical (transitivity patterns) analysis in order to pinpoint in one way or another the ideological positioning of Soyinka towards gender issues, at least, as it is construed in The Lion and the Jewel. The work has been criticized from a feminist view; the transitivity patterns analysis has allowed us to shed the light on how characters construe their experiences through the language they use. It has been hypothesized in the study that The Lion and the Jewel cannot only be considered about the representation of African customs and traditions in some of their aspects and the influence of the modern world on Africans but also about gender. From the analyses, it can be seen that men are represented as dominators of the public space (teacher, chief), capable of concrete, tangible actions, and women as the goals and/or the beneficiaries of men's actions. Both men and women use mental processes, yet women resort to using them more than men. This can lead to qualifying women as emotional beings. In addition, the relational processes analysis indicates that men always view women as an object that they must possess at all costs (the jewel). How they describe others is closely linked to how they describe themselves: intelligent, powerful, and self-confident. While male characters are preoccupied with how they are, female characters insist on what they look like in their use of attributes. Further, the data collected and analyzed in a critical discourse analysis account indicates the construction of ideological power in social institutions such as family, marriage, chieftaincy in which males are the dominators and women dominated.

Izabel Magalhães (2005), in an article entitled 'Interdiscursivity, gender identity, and the politics of literacy in Brazil's using a Feminist Critical Discourse Analysis: Gender Power and Ideology has analyzed women identities through different genres. The methodology used is Feminist Critical Discourse Analysis. That methodology reveals four women's identities through the study. The study aimed at investigating the hybridity of adverts as discourse technologies and to look at the ways in which the self is constructed in relation to the other, through the voices represented in the genre. She has noticed that women and men take part equally in text production. Those texts represent women as workers and writers. In-class discussion (Adult Literacy Programme in Brasil) and in interviews with learners of Catholic Church University, women are seen having the traditional identities as 
mother/housewives. In the advertisement, she sees a global discourse that constructs women's representation as 'bodies with a market price' (p.197).

Koussouhon's (2009) analysis of Ayi Kwei Armah The Beautiful Ones Are Not Yet Born (1966), has revealed a contrast between the abundance of material processes and the lack of Causatives in the texts studied. The lack of Causative processes, he argues, points to the evidence that nobody gets anybody to do anything in order to bring about a change in the novel plot. The analyst's final interpretation of his findings is that the novel depicts a world of ineffectuality and pessimism [...] which is "Ghana's as viewed by Ayi Kwei Armah". Such interpretation is not far-fetched and fantasy-oriented; it is actually based not only on the occurrence of foregrounding in the texts but also on verbalization and symbolic articulation leading to the formulation of verbal art. At least there is hardly any doubt that the analyst has in mind the verbal art in the text as he interprets his findings.

Wahyudin (2016), while analyzing the process types used in News Item, has based his study on Systemic Functional Grammar established by Halliday. The procedure guiding the analysis involves corpus identification, clause labeling, and numbering, and word count. According to the author, analyzing news items may give valuable insight to the learner so that they can experience the language from different kinds of topics existing on the news item. This may also help the EFL learners in Indonesia to learn English better. Results point out that verbal processes are the most used, followed by material processes, mental processes and then, relational processes. Some interpretations are derived from these results. Since the most dominant process type that occurs in the text is a verbal process, the author deduces that the writer is trying to persuade the reader by including some quotations from the important person who is in charge of the project being talked about. The presence of this Sayer may constitute and emerging attempts to construe the representation which can promote the credibility and accuracy of the news being imparted. By adding the result of several studies in the text, the writer attempts to convince the reader and it may lead the public opinion to agree on the project of a nuclear plant.

Having learned about how, several research works have been conducted through the Transitivity pattern, especially from identifying and discussing different process types, we can now get to the heart of our matter. But a remark should be done: our study will have a little bit different from the ones explored in the literature review that is we will also focus on indirect speeches.

\subsection{Research Method}

To reach the target of this research, the methodology designed and adopted is the following: four extracts have been culled from the novel, representing the sample; those selected extracts purposefully selected are submitted to a Systemic Functional Linguistic analysis of the experiential meaning. After splitting each sentence into its clauses, each clause has been split into constituents. The second part of the work consists of identifying indirect speech clauses present in the different extracts. The Transitivity patterns, identified, are counted and encoded in tables of statistics for the sake of quantitative analysis. These data are then linguistically be examined to bring out the novels' experiential meaning. Further, statistical tables have been drawn up for better visibility of the linguistic features displayed by the analyzed extracts, and for a better interpretation of the findings.

\section{Practical Analyses}

In order to have sufficient data that allow us to discuss some passages of the novel, an analysis of some extracts is required. The ongoing section is dedicated to that end. As matter of fact, the analyses are carried out in two stages: analyses of transitivity and analyses of indirectly reported speeches.

\subsection{Transitivity Analysis}

\subsubsection{Analyses of Transitivity in Extract 1}

Table 3.1: Statistics of the Different Processes of Extract 1

\begin{tabular}{|c|c|c|c|c|c|}
\hline \multicolumn{2}{|c|}{ Process Types } & \multicolumn{2}{|c|}{ Extract 1} & \multicolumn{2}{|c|}{ Percentage (\%) } \\
\hline \multirow[t]{2}{*}{ Material } & Transitive & 112 & \multirow[t]{2}{*}{255} & 23.83 & \multirow[t]{2}{*}{54.26} \\
\hline & Intransitive & 143 & & 30.43 & \\
\hline \multicolumn{2}{|l|}{ Mental } & \multicolumn{2}{|l|}{42} & \multicolumn{2}{|l|}{8.94} \\
\hline \multicolumn{2}{|l|}{ Behavioral } & \multicolumn{2}{|l|}{18} & \multicolumn{2}{|l|}{3.83} \\
\hline \multicolumn{2}{|l|}{ Verbal } & \multicolumn{2}{|l|}{31} & \multicolumn{2}{|l|}{6.6} \\
\hline \multirow{4}{*}{ Relational } & Intensive & 106 & \multirow[t]{4}{*}{123} & 22.55 & \multirow[t]{4}{*}{26.17} \\
\hline & Possessive & 14 & & 2.98 & \\
\hline & Causative & 0 & & 0 & \\
\hline & Circumstantial & 3 & & 0.64 & \\
\hline \multicolumn{2}{|l|}{ Existential } & \multicolumn{2}{|l|}{1} & \multicolumn{2}{|l|}{0.21} \\
\hline \multicolumn{2}{|l|}{ Total } & \multicolumn{2}{|l|}{470} & \multicolumn{2}{|l|}{100} \\
\hline
\end{tabular}




\subsubsection{Reporting the Findings from Transitivity Analysis in Extract 1}

As table 3.1 above exudes, extract one is packed with the six process types expanded in the four hundred and seventy (470) clauses of the extract. Almost all process types can be found inside but causative relational processes. Material processes represent more than half of all the processes in the extract (255/469 representing 54.26\%). Outnumbering the other processes, they are prevailed by intransitive material processes (143 representing 30.43\%); transitive material processes represent $23.83 \%$ ( 112 transitive material processes). Those scores suggest that the first extract is more about the process of doing, real tangible actions. Relational processes rank second place with one hundred and twenty-three (123) processes, representing $26.17 \%$. In this latter category, intensive relational processes are the widest spread [106 processes (22.55\%)], followed by possessive relational processes [14 processes $(2.98 \%)]$ and then circumstantial relational processes [3 processes $(0.64 \%)]$. Those statistics suggest that the writer used an important rate of description of actions and participants in this extract. The use of possessive relational processes [14 (2.98\%)] and circumstantial relational processes [3 $(0.64 \%)]$ is very low. Furthermore, the use of mental processes by the author [ 42 mental processes (8.96\%)] shows that the extract also deals with the psychological moods (thoughts, feelings, and perceptions) of the characters (sensers). Verbalized actions are expressed through verbal processes [31 processes (6.6\%)]. There are a few behavioral processes (3.83\%) and only one existential process. Those different results are presented on the diagram below:

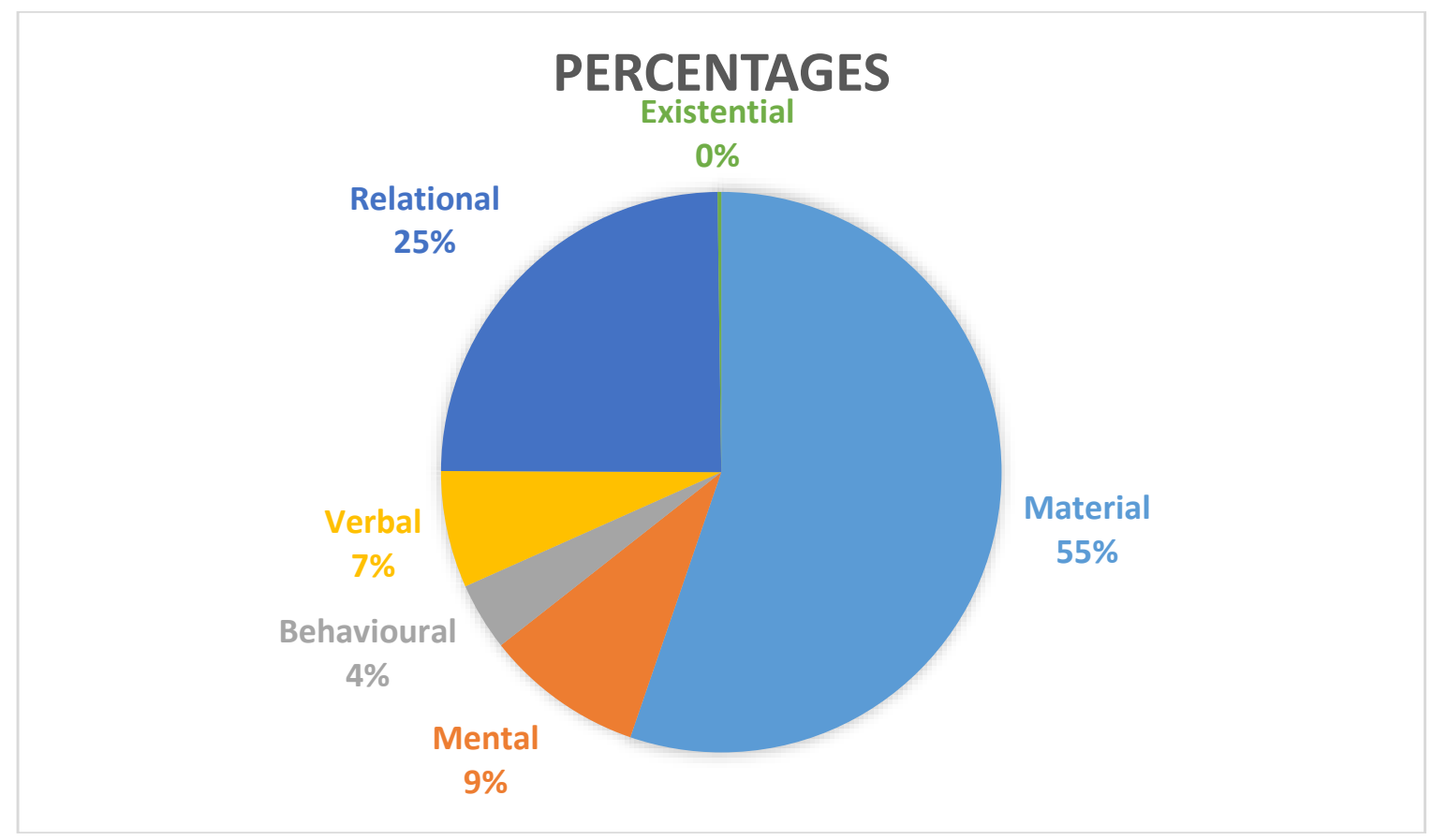

Figure 3. 1: Distribution of Process Types in Extract 1

\subsubsection{Analyses of Transitivity in Extract 2}

Table 3. 2: Statistics of the Different Processes of Extract 2

\begin{tabular}{|c|c|c|c|c|c|}
\hline \multicolumn{2}{|c|}{ Process Types } & \multicolumn{2}{|c|}{ Extract 2} & \multicolumn{2}{|c|}{ Percentage } \\
\hline \multirow{2}{*}{ Materia } & \multirow{2}{*}{$\begin{array}{l}\text { Transitive } \\
\text { Intransitive }\end{array}$} & 108 & \multirow[b]{2}{*}{225} & 23.18 & \multirow[t]{2}{*}{48,28} \\
\hline & & 117 & & 25.11 & \\
\hline \multicolumn{2}{|l|}{ Mental } & \multicolumn{2}{|l|}{60} & \multicolumn{2}{|l|}{12.88} \\
\hline \multicolumn{2}{|c|}{ Behavioral } & \multicolumn{2}{|l|}{32} & \multicolumn{2}{|l|}{6.87} \\
\hline \multicolumn{2}{|l|}{ Verbal } & \multicolumn{2}{|l|}{35} & \multicolumn{2}{|l|}{7.51} \\
\hline \multirow[t]{4}{*}{ Relational } & Intensive & 97 & \multirow{4}{*}{110} & 20.82 & \multirow[t]{4}{*}{23.61} \\
\hline & Possessive & 11 & & 2.36 & \\
\hline & Causative & 2 & & 0.43 & \\
\hline & $\begin{array}{l}\text { Circumstantia } \\
\text { I }\end{array}$ & 0 & & 0 & \\
\hline \multicolumn{2}{|c|}{ Existential } & \multicolumn{2}{|l|}{4} & \multicolumn{2}{|l|}{0.86} \\
\hline \multicolumn{2}{|l|}{ Total } & \multicolumn{2}{|l|}{466} & \multicolumn{2}{|l|}{100} \\
\hline
\end{tabular}




\subsubsection{Reporting the Findings from the Transitivity Analysis in Extract 2}

The statistic data generated through the linguistic description extract two are almost similar to the ones of extract one. The material process shows preponderance in its occurrences. Its frequency almost halves the overall process types occurrences in the passage: [225/466] representing 48.28\%. Likewise, the first extract, intransitive material processes [117 (25.11)] outnumber transitive material processes; so this extract is also predominated by processes of doing, concrete, real, tangible actions. Relational processes rank second with $23.61 \%$ with $20.82 \%$ of intensive relational processes and $2.36 \%$ possessive relational processes. The rate of causative relational processes is insignificant (2\%) while circumstantial relational processes are absent. That suggests that the author did not care about the causes and circumstances of events in that extract. The rate of mental processes isn't negligible, though lower in comparison with the two groups of previous processes [60 processes (12.88\%)]. The proportions of the other processes are a little bit higher than their proportions in the first extract. Their proportions are represented in the diagram below:

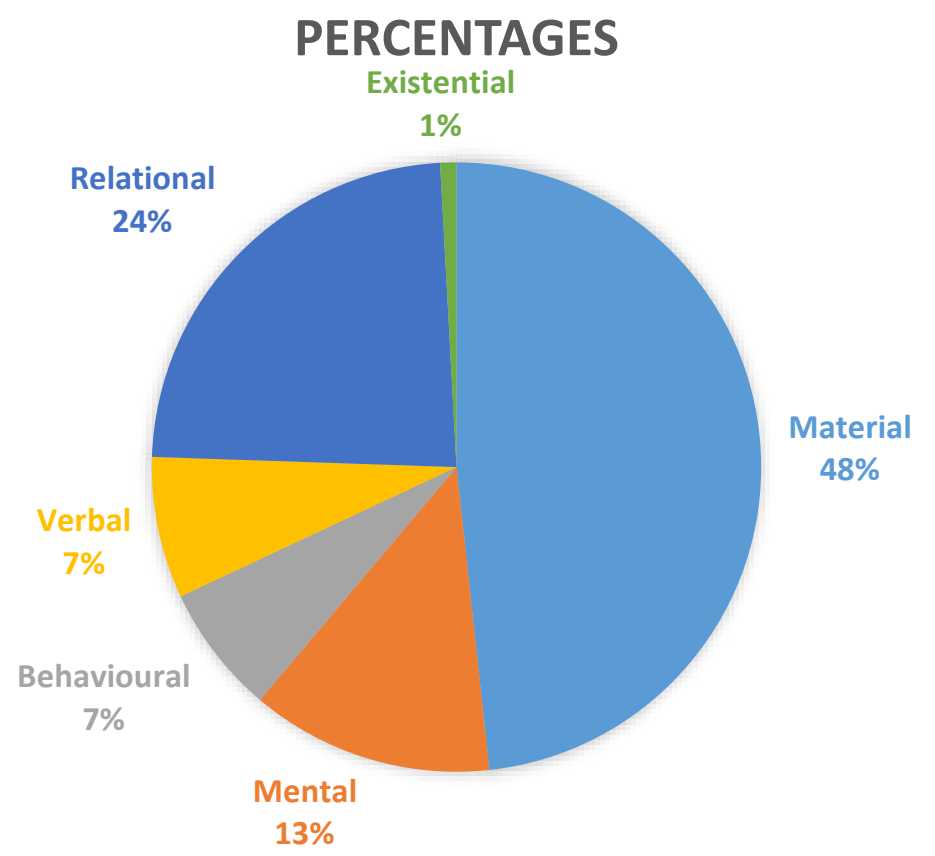

Figure 3.2: Distribution of Process Types in Extract 2

\subsubsection{Transitivity Analysis in Extract 3}

Process types analysis has been conducted in extract two in line with the principles propounded by Eggins (2004); Koussouhon and Dossoumou (2015); and Koutchadé (2015).

Table 3.3: Statistics of the Different Process types of Extract 3

\begin{tabular}{|c|c|c|c|c|c|}
\hline \multicolumn{2}{|c|}{ Process types } & \multicolumn{2}{|c|}{ Extract 3} & \multicolumn{2}{|c|}{ Percentage } \\
\hline \multirow[t]{2}{*}{ Material } & Transitive & 122 & \multirow[t]{2}{*}{223} & 24.21 & \multirow[t]{2}{*}{44.25} \\
\hline & Intransitive & 101 & & 20.04 & \\
\hline \multicolumn{2}{|l|}{ Mental } & \multicolumn{2}{|l|}{67} & \multicolumn{2}{|l|}{13.29} \\
\hline \multicolumn{2}{|l|}{ Behavioral } & \multicolumn{2}{|l|}{28} & \multicolumn{2}{|l|}{5.56} \\
\hline \multicolumn{2}{|l|}{ Verbal } & \multicolumn{2}{|l|}{46} & \multicolumn{2}{|l|}{9.13} \\
\hline \multirow[t]{4}{*}{ Relational } & Intensive & 125 & \multirow[t]{4}{*}{132} & 24.80 & \multirow[t]{4}{*}{26.19} \\
\hline & Possessive & 4 & & 0.79 & \\
\hline & Causative & 0 & & 0 & \\
\hline & Circumstantial & 3 & & 0.6 & \\
\hline \multicolumn{2}{|l|}{ Existential } & \multicolumn{2}{|l|}{8} & \multicolumn{2}{|l|}{1.59} \\
\hline \multicolumn{2}{|l|}{ Total } & \multicolumn{2}{|l|}{504} & \multicolumn{2}{|l|}{100} \\
\hline
\end{tabular}

\subsubsection{Reporting the Findings from Transitivity Analysis in Extract 3}

Extract 3 is specific at one point; with its preponderance in the passage, the material process is widespread [223 occurrences (44.25\%)], unlike the other process types. The disaggregation of this frequency of material type yields 122 transitive and 101 intransitive, all of which fall under the umbrella of material process. This is a testimony that the writer has used more transitive 
material processes than intransitive ones. The passage is therefore a rendition of concrete and tangible actions done by an animate or inanimate being to another one.

Relational process types rank second with a frequency of 132 , making $26.19 \%$ out of which the majority are scored as intensive relational (24.80\%) while possessive and circumstantial relational account respectively for $(0.79 \%)$ and $(0.6 \%)$ relational processes. The causative relational process is definitely absent in the extract. Mental processes and verbal processes are present in considerable proportions (respectively 13.29\%, 9.13\%). The existential process shows the lowest frequency with eight occurrences $(1.59 \%)$ as shown in the diagram below:

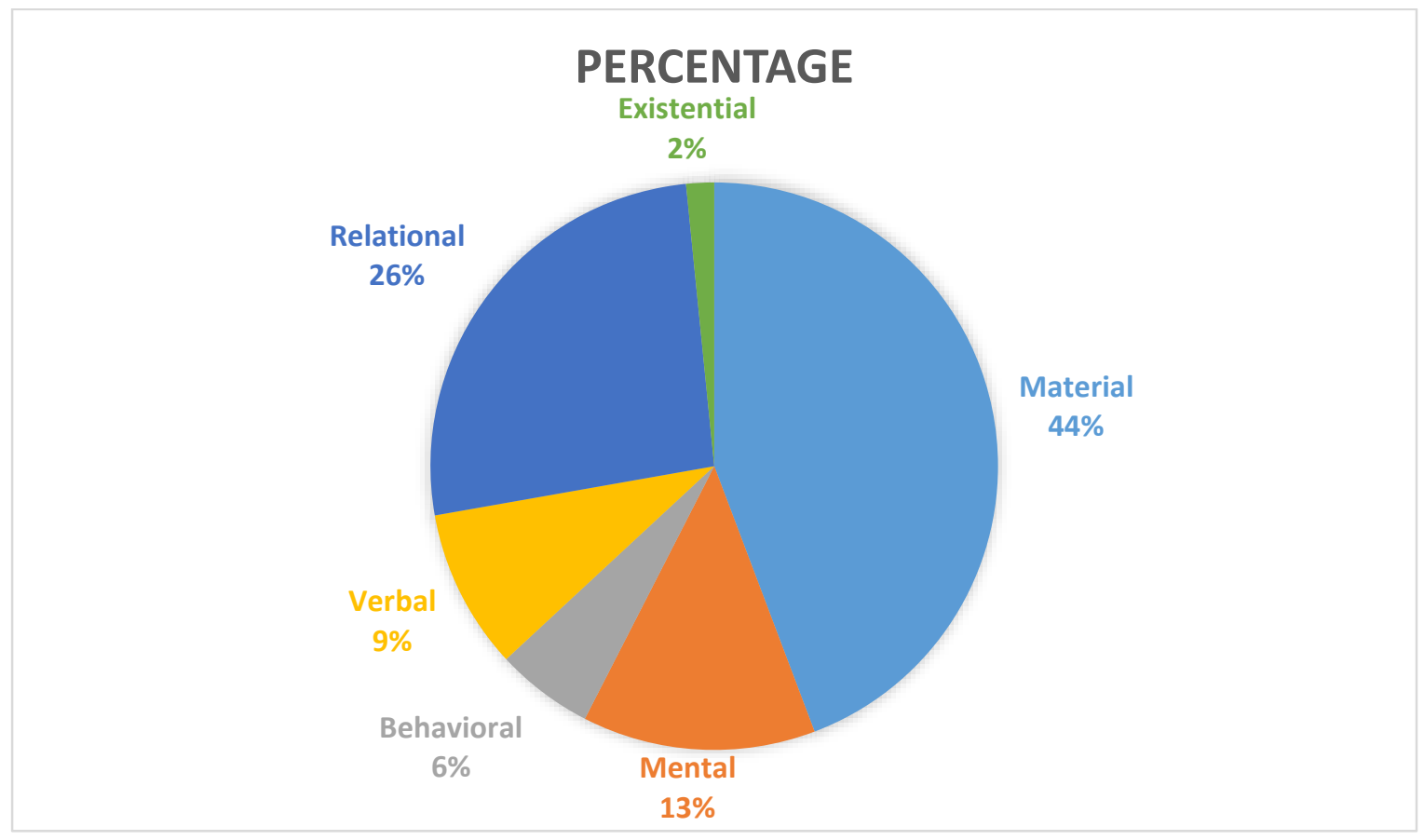

Figure 3. 3: Distribution of Process Types in Extract 3

\subsubsection{Analyses of Transitivity in Extract 4}

Table 3. 4: Statistics of the Different Processes of Extract 4

\begin{tabular}{|c|c|c|c|c|c|}
\hline \multicolumn{2}{|c|}{ Process types } & \multicolumn{2}{|c|}{ Extract 4} & \multicolumn{2}{|c|}{ Percentage (\%) } \\
\hline \multirow[t]{2}{*}{ Material } & Transitive & 108 & \multirow[t]{2}{*}{264} & 19.39 & \multirow[t]{2}{*}{47.40} \\
\hline & Intransitive & 156 & & 28.01 & \\
\hline \multicolumn{2}{|l|}{ Mental } & \multicolumn{2}{|l|}{93} & \multicolumn{2}{|l|}{16.70} \\
\hline \multicolumn{2}{|c|}{ Behavioral } & \multicolumn{2}{|l|}{11} & \multicolumn{2}{|l|}{1.97} \\
\hline \multicolumn{2}{|l|}{ Verbal } & \multicolumn{2}{|l|}{38} & \multicolumn{2}{|l|}{6.82} \\
\hline \multirow{4}{*}{$\begin{array}{l}\text { Relation } \\
\text { al }\end{array}$} & Intensive & 136 & \multirow[t]{4}{*}{147} & 24.42 & \multirow[t]{4}{*}{26.39} \\
\hline & Possessive & 11 & & 1.97 & \\
\hline & Causative & 0 & & 0 & \\
\hline & Circumstantial & 0 & & 0 & \\
\hline \multicolumn{2}{|c|}{ Existential } & \multicolumn{2}{|l|}{4} & \multicolumn{2}{|l|}{0.72} \\
\hline \multicolumn{2}{|l|}{ Total } & \multicolumn{2}{|l|}{557} & \multicolumn{2}{|l|}{100} \\
\hline
\end{tabular}

\subsubsection{Reporting the Findings from the Transitivity Analysis in Extract 4}

Here again, in extract 4, the material process seems to be overused by the writer. Indeed, it displays a total of 264 occurrences (47.40\%). One should emphasize the disaggregated distribution of this linguistic feature into the intransitive material process which represents $28.01 \%$ outnumbering the transitive material process, accounting for $19.39 \%$. The relational process occurs at a frequency of 147 (26.39\%) distributed exclusively between intensive (24.42\%) and possessive (1.97\%). The extract contains no 
causative and circumstantial processes. The mental process which encompasses the three sub-types, namely Cognitive, Perceptive and Affective has appeared in the texts in a considerable proportion of 93 occurrences making $16.70 \%$. As for the process of speaking, expressing, voicing, and reporting, it occurs at a frequency of 38 , making $6.82 \%$. The rate of the existential process shows only 4 occurrences making $0.72 \%$. Diagram 3.4 below provides a representation of those proportions.

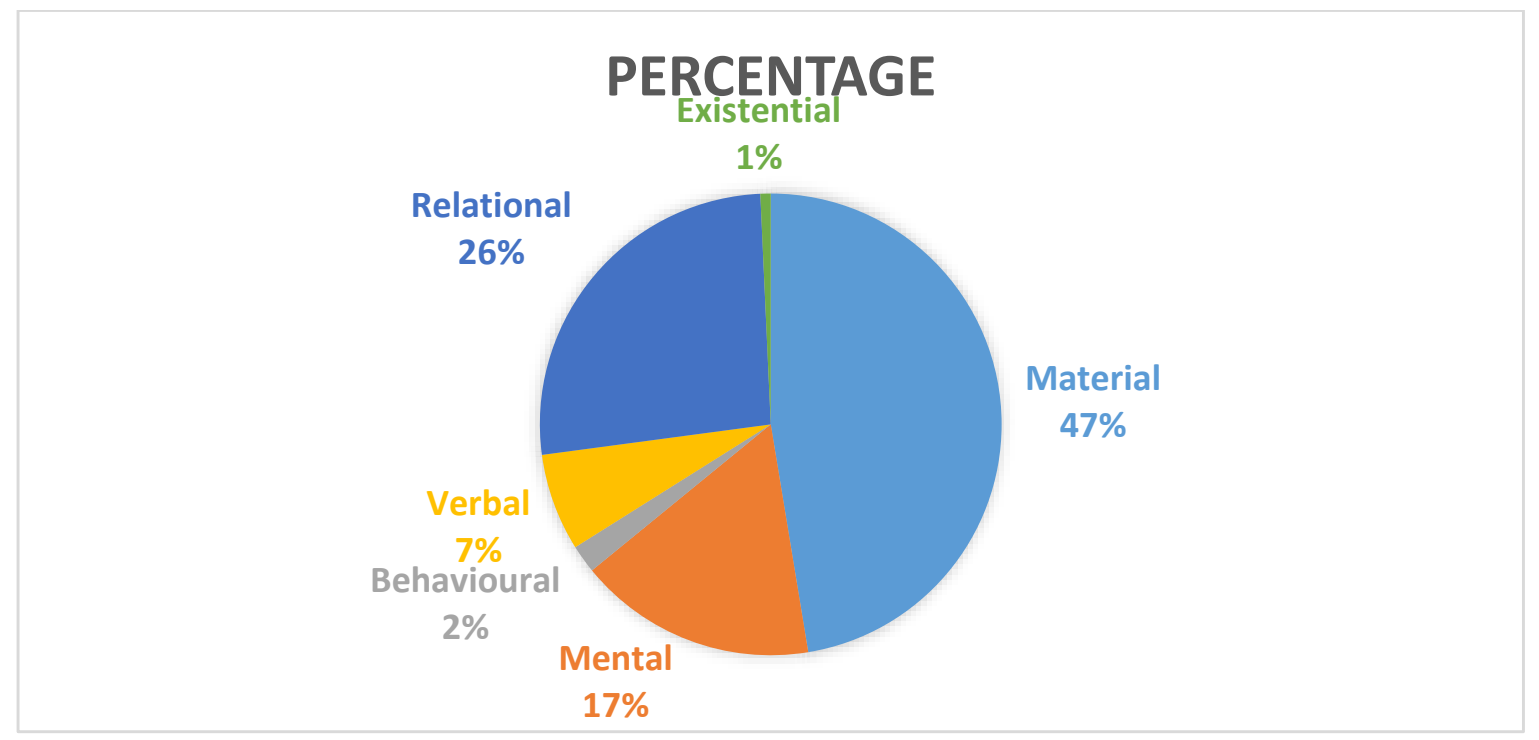

Figure 3. 4: Distribution of Process Types in Extract 4

It should be highlighted that following the various analyses. One observes that the four various extracts show similar trends with the material process overriding the statistics everywhere. This suggests that those specific passages and, the novel, as a whole, are more about the traditional question always asked in Systemic Functional Grammar: who does what to whom, under which circumstances? It must be stated here that the doers of almost all the actions in this novel are frequently animate beings, in particular, human characters like Rufus, Zaq, Tamuno and his son, the Soldiers, the Doctor, Naman (the Priest), Gloria (the nurse), the kidnappers, the Professor, Mr. and Mrs. Floode. The relational process with its different sub-types ranks second in all 4 extracts. Indeed, it appears that the writer and more specifically the narrator has given a more descriptive rendition in the narrative of the kidnapping of the expatriate lady. Furthermore, the use of the mental process by the writer which ranks third in all extracts shows that the novel also deals with psychological actions (thoughts, feelings, and perceptions) of the characters (sensers), expressing sensers thoughts, feelings, and perceptions. Verbalized actions are expressed through the verbal process. They are the fourth most used process type. There are a few behavioral processes and barely existential processes. Those statistics are summarized in the figure below.

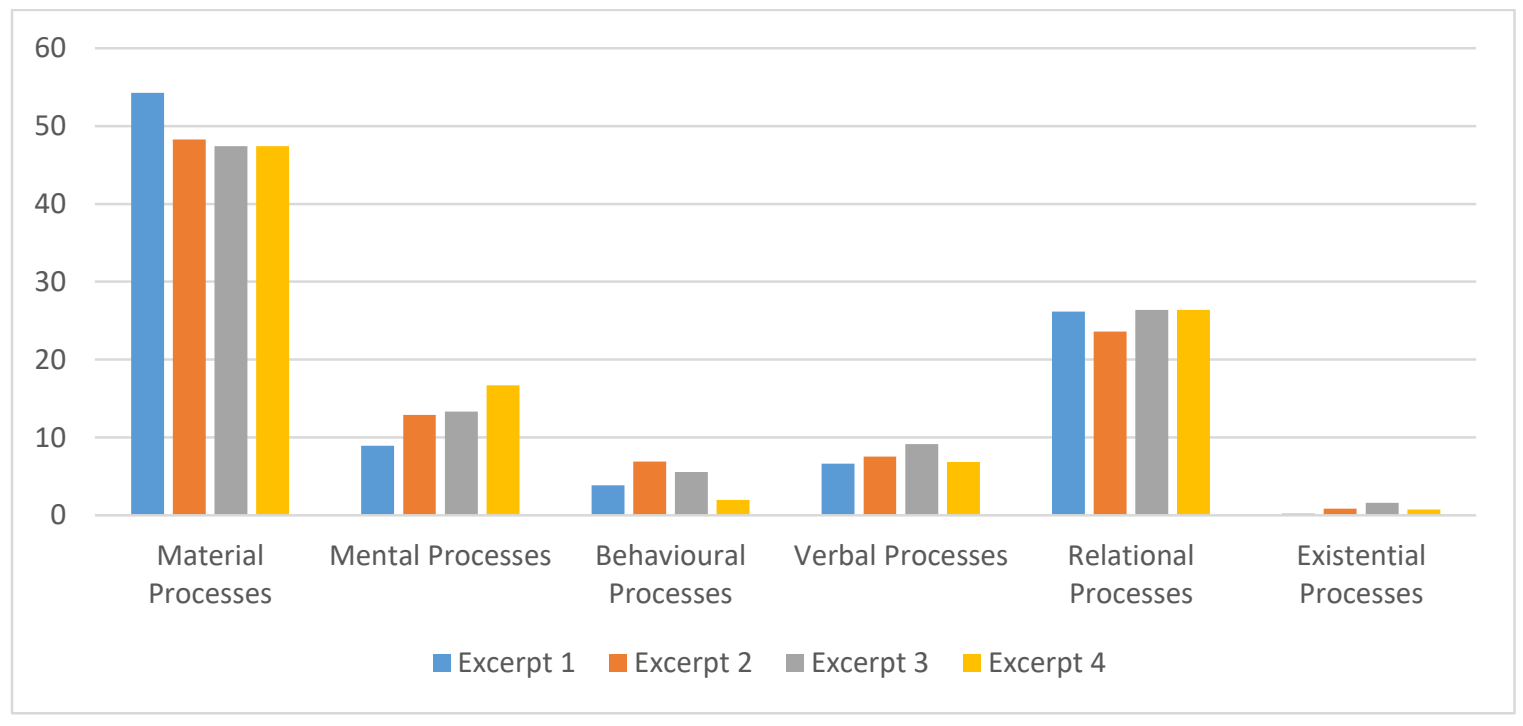

Figure 3. 5: Distribution of Process Types in the Four Extracts 


\subsection{Analyses of Indirect Speeches}

The second part of our analysis is based on the indirectly reported speeches used in the extracts. Rudy Hariyono and Andrew (2008) defined Indirect speech as a sentence that is spoken to convey a person's statement to others. It is a summarized or modified version of the character's original utterance from the reporting speaker's point of view (Coulmas, 1986). Those reported speeches are introduced by verbal process.

\subsubsection{Analyses of Indirect Speeches in Extract 1}

Seven (07) indirect reported speech clauses have been identified in the first extract as follows:

1- Well, the Major[Sy] said[Pv] to treat[TPm] you well[G] till he[A] comes[IPm].

2- I[Sy] asked[Pv] him[Rv] if he[Cr] was[Pi] also a soldier.

3- The Doctor[Sy] (...) asked[Pv] me[Rv] how long he[Cr] had been[Pi] ill[At]..

4- He[Sy] (...) said[Pv] he[A]'d work[TPm] on them[G] and let us know[TPm] what[Cr] was[Pi] wrong [At] by tomorrow[Cl]

5- She[Sy] says[Pv] she[Pr] has[Pp] an offer[Pd] elsewhere[Cl], a fashion magazine, and really she[A] can't waste[TPm] her days[G] sitting $[\mathbf{I P m}]$ in some anteroom $[\mathbf{C l}]$ trying to figure out[TPm] silly riddles[G] about Siberia[Ct].

6- Your CV[Sy] (...), says[Pv] you[A] has done[IPm] some photography.

7- I[Sy] told[Pv] them I[A]'d write[TPm] it not as a kidnapping story only, but I[A]'d try to find out[TPm] what kind of woman the hostage[Cr] was[Pi]: if she[Pr] had[Pp] children[Pd], if she[S] regretted[Pme] coming to Nigeria, if she[Pr] had[Pp] any message for her husband [Pd].

Table 3.5: Distribution of the Reporter's Use of Indirect Speeches in the Extract 1

\begin{tabular}{lll}
\hline Indirect reported speech & Reporter & Sayer \\
1 & Soldiers & The Major \\
2 & Rufus & Rufus \\
3 & Rufus & The doctor \\
4 & Rufus & The doctor \\
5 & Rufus & The girl (blogger) \\
6 & The editor & CV \\
7 & Rufus & Rufus \\
\hline
\end{tabular}

It follows from those clauses that the speeches indirectly reported in extract 1 have been used by three "reporters", namely: Soldiers, Rufus, and the Editor. Rufus is the one who reports the majority of clauses (5/7) and to a large extent the major part of the story in the novel.

\subsubsection{Indirect Speeches Identification and analysis in Extract 2}

In that extract, we have identified eleven reported speech clauses that are:

1- But he $[\mathbf{S y}]$ said $[\mathbf{P v}]$ they $[\mathbf{A}]$ only came $[\mathbf{I P m}]$ because she $[\mathbf{C r}]$ was $[\mathbf{P i}]$ seriously ill, and they[S] knew[Pme] we $[\mathbf{P r}]$ had $[\mathbf{P p}]$ a nurse[Pd] here[Cl].

2- They [Sy] said [Pv] they[Cr]'d be [Pi] on their way[At]

3- They $[\mathbf{S y}]$ said $[\mathbf{P v}]$ they $[\mathbf{A}]$ were still waiting $[\mathbf{T P m}]$ for the Professor[G] to return[IPm]

4- The rest, he [Sy] said[Pv], had been killed [IPm] in the fight with the soldiers.

5- He [Sy] said [PV] they [A] had to leave [IPm] at once.

6- But Zaq[Sy] said[Pv] he[Cr] wasn't[Pi] hungry[At]..

7-She [Sy] said [Pv] there were $[\mathbf{P e}]$ very few such tenement houses[X] in the village $[\mathbf{C l}]$,

Since there wasn't $[\mathbf{P e}]$ much need[X] for them, the village $[\mathbf{C r}]$ being [Pi] without any form of industry to attract[TPm] outsiders[G]

8- He [Sy] said[Pv] you[Sy] told [Pv] him that you[S] think[Pme] I[Cr]'m[Pi] attractive[At]?

9- Naman[Sy] told[Pv] me you[Sy] were going to ask[Pv] me that.

10- And he[Sy] said to tell[Pv] you all I[S] know[Pme].

11- Well, afterwards one of the men[A] (...) told[Pv] me if I[Sy] talked[Pv] about the woman or about the men to anyone[Ct], terrible things[Cr] would happen[Pi] to the community[At], and it[Cr] would be[Pi] my fault[At]. 
Table 3. 6: Distribution of the Reporter's Use of Indirect Speeches in the Extract 2

\begin{tabular}{|l|l|l|}
\hline Indirect reported speech & Reporter & Sayer \\
\hline 1 & Naman & Professor \\
2 & Naman & Kidnappers \\
3 & Naman & Kidnappers \\
\hline 4 & Naman & Professor \\
5 & Naman & Professor \\
6 & Rufus & Zaq \\
\hline 7 & Rufus & Gloria (The nurse) \\
\hline 8 & Gloria (The nurse) & Zaq \\
9 & Gloria (The nurse) & Naman \\
\hline 10 & Gloria (The nurse) & Naman \\
11 & Gloria (The nurse) & Kidnappers \\
\hline
\end{tabular}

Clauses enshrined in the above-mentioned eleven reported speeches are reported by Naman, Rufus, and Gloria. Naman (the priest) and Gloria (the nurse) are those who have reported the maximum of speeches (5/11 for Naman and 4/11 for Gloria). The main reason substantiating such uneven distribution is the fact that they are eye-witnesses of the turmoil and other events that happened in the village. They are not only in the position of storytellers but also that of events reporters, just like the messengers conveying messages to the villagers.

\subsubsection{Analyses of Indirect Speeches in Extract 3}

One can notice that only five (05) reported clauses are identified in extract 3 . There are as follows:

1- They [Sy] said [Pv] it[Cr] was[Pi] a sign[At], the fulfillment of some covenant with God.

2- The manager $[\mathbf{A}]$, an Italian guy, wrote $[\mathbf{T P m}]$ me a check $[\mathbf{G}]$ and said $\mathbf{P} \mathbf{P v}] \mathbf{I}[\mathbf{C r}]$ was $[\mathbf{P i}]$ now on their payroll.

3- He [Sy] told [PV] me $[\mathbf{R v}]$ to continue doing [IPm] what I[A] was doing [IPm], but this time I [A] was to come [IPm] only to him[G] with my results.

4- The Doctor [Sy] said [Pv] it [Cr] would be [Pi] like this $[\mathbf{C m}]$, good days alternating $[\mathbf{P e c}]$ with bad ones.

5- The Doctor [S] here told [Pv] me that one of your plans [A] on this trip is to interview [TPm] the Professor [G], yes?

Table 3.7: Distribution of the Reporter's Use of Indirect Speeches in the Extract 3

\begin{tabular}{|l|l|l|}
\hline Indirect speech clause & Reporter & Sayer \\
\hline 1 & The doctor & Villagers \\
\hline 2 & The doctor & The manager \\
\hline 3 & The doctor & The manager \\
\hline 5 & Rufus & The doctor \\
\hline
\end{tabular}

Three "reporters" have reported the indirect speeches identified in the passage. Those reporters are the medical Doctor who reported 3 out of 5 clauses (3/5), Rufus (1/5) then the major (1/5).

\subsubsection{Analyses of Indirect Speeches in Extract 4}

There are eighteen reported speech clauses in the $4^{\text {th }}$ extract. Here are those speeches:

1- He [Sy] said [Pv] Chief Ibiram and his people [A] had left [IPm] their settlement [Cl] late the previous night [Cl], preferring to travel [Pme] under cover of darkness [Cl],

2- and by his estimate that[A] put[IPm] them at least ten hours ahead of us, but because they[Pr] had[Pp] children and women[Pd] they'd be forced to stop[IPm] often.

3- I [Sy] told [Pv] the two men to slow down [IPm] for a minute [CX]

4- When she $[\mathbf{S y}]$ asked $[\mathbf{P v}]$ him $[\mathbf{R v}]$ if he $[\mathbf{A}]$ was $[\mathbf{P i}]$ happy $[\mathbf{A t}]$ with the way things were $[\mathbf{P i}]$ if he[S] would perhaps think [Pme] of another line of work [Ph] for the sake of their marriage [Cc],

5- he [Sy] told [PV] her [Rv] Nigeria [Cr] would be [Pi] for only two years [Cx], and then he $[\mathbf{A}]$ would retire [IPm].

6- When, in desperation, I[Sy] told[PV] him[Rv] about my intention[Ct] to get[Pi] pregnant, 
7- he[Sy] said[Pv] it[Cr] was[Pi] out of the question[At].

8- And that was[Pi] when he[S] told[Pv] me[Rv] he[A] was seeing[IPm] someone else[G].

9- He[Sy] told[Pv] me[Rv] he[S] wanted[Pme] a divorce[Ph].

10- Well, he[Sy] said[Pv] the affair[A] had been going on [IPm] for a while[CX],

11- and that she[Cr] was[Pi] pregnant[At].

12- Something [Sy] told[Pv] her what she[S] was about to hear[Pme] wasn't going to be[Pi] pleasant[At].

13- Yesterday[Cl] she[Sy] told[Pv] me[Rv] she[Cr] was[Pi] pregnant[At].

14- I[Sy] told[PV] Salomon[Rv] to take me[TPm] to any good hotel[Cl],

15- and he[Sy] suggested[Pv] I[Cr] stay[Pi] there, at his uncle motel[Cl].

16- I[Sy] told[Pv] him to give[TPm] Salomon my things,

17- that I[A] was leaving [IPm] the next day $[\mathbf{C l}]$,

18- that I[A] would call[TPm] him when I[Cr] got[Pi] to London.

Table 3.8: Distribution of Indirect Speeches Use among Characters in Extract 4

\begin{tabular}{|l|l|l|}
\hline No of the indirect speech clause & Reporter & Sayer \\
\hline 1 & Rufus & Charles \\
\hline 2 & Rufus & Charles \\
\hline 3 & Rufus & Rufus \\
\hline 4 & Rufus & Isabel Floode \\
\hline 5 & Rufus & James Floode \\
\hline 6 & Isabel Floode & Isabel Floode \\
\hline 7 & Isabel Floode & James Floode \\
\hline 8 & Isabel Floode & James Floode \\
\hline 9 & Isabel Floode & James Floode \\
\hline 10 & Isabel Floode & James Floode \\
\hline 11 & Isabel Floode & James Floode \\
\hline 12 & Isabel Floode & Something \\
\hline 13 & Salomon & Koko \\
\hline 14 & Isabel Floode & Salomon \\
\hline 15 & Isabel Floode & Salomon \\
\hline 16 & Isabel Floode & Isabel Floode \\
\hline 17 & Isabel Floode & Isabel Floode \\
\hline 18 & Isabel Floode & Isabel Floode \\
\hline
\end{tabular}

As table 3.8 above exudes, Extract for contains speeches reported by three characters interacting therein; they are namely, Rufus, Isabel Floode, and Salomon. Isabel Floode has reported the majority of indirect speeches $12 / 18$, making $66.66 \%$ of the reporting. Rufus has reported five (5/18) and, Salomon (1/18). It indicates that Isabel Floode is the one who related the majority of the story in that extract. She is relating how she has been abducted by the freedom fighters. There are other indirect speeches ingrained in the extract under study. Though very few, those indirect speeches contribute to unraveling some deeper information about the text under study.

It should be pointed out that each extract develops around one "major reporter". Besides, there is another commonality for all the four extracts: Rufus is a crosscutting participant to the four extracts. This typical characterization is obviously correlated to the writer's desire to upgrade his previous journalistic career. Rufus may be construed as an autobiographical narrator/reporter.

\section{Discussions of Findings}

The transitivity analyses of the novel through four selected extracts revealed a similarity in the proportions of the processes used in the novel. This leads us to deduce that the statistics observed in the four extracts represent the general tendency of the whole novel. All the six processes are present in the novel though in different proportions. The process types are respectively according to their predominance material, relational, mental, verbal, behavioral, and existential. The material transitive and intransitive are the most widely used in the novel.

The overuse of material processes entails that Helon Habila's Oil on Water is more about the reality of the events going on in the Niger Delta region. As a matter of fact, this narrative reads like a live portrayal of the real-life situation affecting the oil-resourced region of Nigeria on daily basis. It cannot be overemphasized that the novel has been knowingly crafted to portray the Niger Delta 
region at an overarching period of its history punctuated by the realities of the epoch and sociocultural context (petrobusiness, damages caused by petrol, rebellion, kidnapping, ransoming...). In fact, rebellion, kidnapping, and ransoming are not unknown phenomena in Nigeria. In the reality, one can notice rebel groups like Boko Haram, the Movement for the Emancipation of the Niger Delta (MEND), Niger Delta Avengers; the two latter being specialized in attacks against oil infrastructures and kidnapping, phenomena described in Oil on Water by Helon Habila as showed by the existence of the actors named "kidnappers" in the novel. The kidnappers are bound to carry out real actions which generate concrete results for the benefit of their groups and godfathers. Those tangible actions include kidnapping foreigners for ransom, writing and publishing position papers about the environmental devastation and their reasons for taking up arms against the oil companies and the government. Taking a glance at the reality of Nigeria, we can notice similar events: on November $8^{\text {th }}, 2010$, for example, MEND has kidnapped two Americans, two Frenchmen, two Indonesians, and one Canadian (Allen, 2010).

Moreover, one reading the novel, one realizes that it is a blend of through the novel, we can notice actions undertaken by intellectuals to denounce the environment's pollution and degradation by oil exploitation. The Doctor undertook such an action. In the real-life, we can compare the action of the Doctor to the non-violent campaign of Nigerian prominent writer and environmental activist Ken Saro-Wiwa.

The predominance of relational processes after material ones with a pre-eminence of intensive relational processes reveals the fact that the author took particular attention to describing events and places. In fact, while reading the novel, the descriptions lead us in the world of the actions painted by the author as if we are at the very places at the very moment of the actions. The realism is confirmed by the description of real places like the Niger Delta (especially Port Harcourt), the rivers, the islands. Moreover, the destruction of the shrine looks like the destruction of Odioma, an ancient community located in Bayelsa State (Niger Delta) that happened in 2005 (Polgreen, 2006).

Following the relational process, the mental process comes next; this typology is preponderantly used in the selected extracts. The majority of Senser roles are performed by animate, mainly human beings who are psychologically (intellectually, affectively, and emotionally) evolving throughout the situations and events described in the plot. It suggests that the different protagonists of the narration (journalists, soldiers, rebels) are conscious of the implications of their actions. Each one thinks he is right and his protagonist is wrong. That's why in the novel, rebels would invite the media to explain themselves. It also justified the following affirmations made by the Major about the rebels: "Their life is so miserable, to begin with, and they dream of becoming instant millionaires. It's my job to pursue them to their swamp hideouts. I capture them, and most times it's easier to shoot them than to capture them. Save time, save the government money." In reality, insurgent groups would use various channels and means to explain their point or convey messages pertaining to their positions and claims. In January 2006 for example, MEND warned the oil industry through an email (Howden, 2006).

The verbal processes used by the writer have the particularity of conveying sometimes indirectly reported speeches. Those speeches, though fewer in the passages are indicative of the Sayers, addressees, and verbiages in the narrative. Of course, the persistent use of the verbal process in combination with the recurrently reported speeches, are characteristic of Rufus' way of wording and casting his sentences and phrases. With this revelation, it can be inferred that Rufus is the narrator of the plot, therefore the reporter.

\section{Conclusion}

The foregoing was premised on proving how the interaction between a principle of ideational metafunction and indirect speech could combine to interplay and thereby consolidate meaning expansion in a text. The overall and specific objective formulated in this regard considers a correlation of the interplay between the direct and indirect transitive process as well as the indirect speeches for an insightful alignment and categorization of Helon Habila's Oil on Water (2011). This consists in analyzing Transitivity and Indirect Speech ingrained and identified in some clauses of the passages systematically taken from the novel under study. Systemicists are all cognisant of one cardinal principle guiding Systemic Functional Linguistics through the exploration of transitivity properties (processes, participants, and circumstances) in a text. It is all about coming up to draw conclusions about the question- Who does what to whom in which circumstances? This combination of the writer's inner and outer experiences contributes to deciphering the experiential meaning and indirect speech as expounded and conveyed in the passages serving as corpus beyond the mere words used in the novel so as to provide accurate answers to the previously set research questions.

As a matter of fact, when studies in text linguistics combine the devices of indirect discourse, direct and indirect transitive process with their various participants and circumstances, to describe fictional or real-life texts, they definitely succeed in unraveling all the lexical and grammatical properties ingrained therein. These linguistic sterling beads contribute to decrypting the stylistic beauty and understanding of the participants' ecology roles and sometimes work as evidence and testimony of journalistic creativity and reporting experience. 
The linguistic description through the identification of the direct, indirect material process of various passages in Oil on Water (2011) has revealed a similar trend across the extracts regarding the profuse materialization of the novel, as a whole, but only with a slight difference. Other process types also have been identified in the passages, going from relational to existential, passing through verbal and behavioral.

The mental proves with its animate human beings performing as Sensers and Phenomena to having propounded cognitive, perceptive, and affective processes. These mental varieties are evidence that the passages studied and the novel as a whole deal with events and actions which involve the psychological mood and emotional stability of the participants. It should be singled out the fact that the verbal processes are used by human Sayers who have operated the majority of those reported speeches identified in the passages. Those characters are mainly Rufus, Isabelle Floode, Gloria (The nurse), Soldier, Naman, and Solomon.

Though not too preponderant throughout the passages analyzed, indirect or reported speeches are identified in the passages to enable readers to be abreast of the reality being portrayed in the novel. Though it appears that each extract is moderated by its narrator, there is a lead or main narrator of the whole story, Rufus, the reporter who takes the reader along, to convey and impart all the events developed around the Niger Delta region.

From the foregoing discussion, it can be inferred that even though the novel is fiction, Helon Habila has used this narrative to portray some topical realities of his epoch in his homeland. He as a writer has leveraged on his journalistic experience to unravel, depict and report the cankers caused by oil exploitation, namely environmental pollution, ecological destruction, ecosystem disturbance as well as the insecurity and instability which occur as a result of the native population's revolt against the damager of their cultural and agrarian heritage. Indeed, these literary deductions come to evidence along with the other various linguistic ingredients revealed that the novel is loaded and packed with real-life situations, concrete actions, and tangible events performed by conscious animate participants. Their assignments from the way they have been designed, created, and fashioned by the writer are about helping voice, report, bear, and uncover the veil on those multiple unacceptable cankers through a fictional dramatization of the ongoing socio-ecological, security, and political events.

Furthermore, Helon Habila has taken his readership in a contextualized and dramatized world close to one of social, ecological, political, and security situations prevailing in the Niger Delta of Nigeria. This paper may therefore venture to infer that the novel under study is a great topical literary artifact that has been produced at an overarching period to portray contemporary Nigeria. Regarding the research questions raised from the inception of this study, one can dare say that the various answers provided have simultaneously brought the research objectives to fruition, though many other linguistic, sociolinguistic, and pragmatic aspects could still contribute to delivering more either considered individually or collectively in an integrated approach.

\section{References}

[1] Akogbeto, C. P., Koukpossi O. A. (2015). Gender Issues in the Lion and the Jewel by Wole Soyinka: A Linguistics-Oriented Analysis from a Systemic Functional Grammar and Critical Discourse Analysis Perspective. Communication and Linguistics Studies. 1(2), 26-34. doi:10.11648/j.cls.20150102.13

[2] Alaei, M., Ahangari, S. (2016). A Study of Ideational Metafunction in Joseph Conrad's "Heart of Darkness": A Critical Discourse Analysis. English Language Teaching, Vol.9, (No. 4)

[3] Arunsirot, S. (2013). An Analysis of Textual Metafunction In Thai Efl Students Writing. Novitas-ROYAL (Research on Youth and Language), $7(2), 160-174$

[4] Boukari, N., Koussouhon, A. L. (2018). Transitivity Analysis of Gabriel Okara's The Voice. International Journal on Studies in EnglishLanguage and Literature, 6, 1-15

[5] Caffarel, A., Martin, J. R., Matthiessen, C. M. I. M. (2004) Language Typology: A Functional Perspective. London: John Benjamins Publishing.

[6] Coulmas, F. (1986). Direct and Indirect Speech. New York: Mouton de Gruyter.

[7] Eggins, S. (2004). An Introduction to Systemic Functional Linguistics (2 ${ }^{\text {nd }}$ ed.).London: Pinter

[8] Halliday, M. A. K., Webster, J. (2006). On Language and Linguistics. London: Continuum

[9] Hariyono, R., Mc. Carthy, A. (2008), ABC Plus English Grammar. Surabaya: Gitamedia Press

[10] Harbi, S. (2019). 'Hey, Jude! Wanna Hold Your Hand': Transitivity Process Analysis on Popular Songs by The Beatles. International Journal of Language Education and Applied Linguistics, 9(1),45-54.

[11] Habila, H. (2011). Oil on Water. London: Penguin Books.

[12] Howden, D. (2006). Corp Watch: NIGERIA: Shell may pull out of Niger Delta after 17 die in boat raid.

[13] Koussouhon, A. L. (2009). Process types and Ideational Meaning in The Beautiful Ones Are Not Yet Born, in IMO-IRIKISI, 1,129-142.

[14] Koussouhon A. L., Dossoumou A. M. (2015). Exploring Ideational Metafunction in Helon Habila's Oil on Water: A re-evaluation and redefinition of African Women's Personality and Identity through Literature. International Journal of Applied Linguistics \& English Literature, 4(5), 129-136,

[15] Koutchadé, I. S. (2015). Discourse Analysis of General Muhammadu Buhari's Official Acceptance Speech: A Systemic Functional Perspective. International Journal of English Linguistics, 5(5), 24-36. http://dx.doi.org/10.5539/ijel.v5n5p24

[16] Kuswoyo, H. (2014). A Systemic Functional Grammar Analysis: Perception Verbs as Found in Jane Austen's Pride and Prejudice. The 1 $7^{\text {st }}$ International Seminar on Linguistics (ISOL-I) 142-150. 
[17] Magalhães, I. M. (2005). Interdiscursivity, gender identity and the politics of literacy in Brazil, in Lazard, M. (ed.), Feminist Critical Discourse Analysis and Ideology in Discourse. New York: Palgrave, 181-204

[18] Mayr, A. \& Machin, D. (2012). The Language of Crime and Deviance: An Introduction to Critical Linguistic Analysis in Media and Popular Culture. London and New-York: Continuum.

[19] Ong'onda, N. A.(2016). Transitivity Analysis of Newspaper Headlines on Terrorist Attack in Kenya: A Case Study of Westgate Mall, Nairobi. International Journal of Humanities and Social Sciences, 6(9), 77-85. DOI: https://doi.org/10.33365/ts.v14i1.79

[20] Polgreen, L. (2006). Blood Flows with Oil in Poor Nigerian Villages. New York: New York Times.

[21] Wahyudin, Y. A. (2016). A Study of Transitivity System: An Analysis of Process Type Used in News Item. Teknosastik :in Journal Bahasa dan Sastra. Vol. 14, Issue 1. Universitas Teknokrat Indonesia 